\title{
Effect of Cadmium on Lipid Peroxidation and on Some Antioxidants in the Liver, Kidneys and Testes of Rats Given Diet Containing Cadmium-polluted Radish Bulbs
}

\author{
Samir Haouem ${ }^{1 *}$, and Abdelhamid El Hani ${ }^{1}$ \\ ${ }^{1}$ Departement de Physiologie, Faculté de Médecine de Monastir, 5019 Monastir, Tunisie
}

\begin{abstract}
The aim of this study was to examine the effects of cadmium (Cd), incorporated in radish bulbs, on malondialdehyde and glutathione levels and on superoxide dismutase activity in the liver, kidneys and testes of male rats. The control animals were given diet containing ordinary radish bulbs for 4,8 and 12 weeks, while contaminated animals were given diet containing Cd-polluted radish bulbs (1.1 $\mathrm{mg} \mathrm{Cd} / \mathrm{g}$ of diet) for the same periods as in the controls. At each time point, rats were euthanized and the liver, kidneys and testes were removed. The results indicated that the body weight gain of contaminated rats was identical to that of the control rats. $\mathrm{Cd}$ concentrations in the liver, kidneys and testes increased significantly and gradually from the 4th to 12th week of treatment. Malondialdehyde concentrations decreased significantly in the liver and increased significantly in the kidneys and testes after 12 weeks of treatment, while glutathione levels increased significantly in the liver, and decreased significantly in the kidneys and testes at the same time. No changes were observed in SOD activity in the liver, while in the kidneys and testes, this activity was increased after 12 weeks of treatment as compared with the control rats. (DOI: 10.1293/tox.2013-0025; J Toxicol Pathol 2013; 26: 359-364)
\end{abstract}

Key words: cadmium, liver, kidney, testes, oxidative stress, rat

\section{Introduction}

Living beings are evolving today in environments polluted by different types of pollution. Heavy metals are the most dangerous groups of anthropogenic environmental pollutants and are highly toxic and persist in the environment ${ }^{1}$. Cadmium is one of the most toxic heavy metals. It is a nonessential trace element that is toxic to plants and animals ${ }^{2}$. This metal is not always present in the environment in the metallic state but is often present as a mineral combined with other elements ${ }^{3}$. It is widely distributed in the earth's crust, where it exists at concentrations of about 0.1 to $0.2 \mathrm{mg} / \mathrm{kg}$ of soil associated with zinc and lead ${ }^{4}$.

Transfer of cadmium through the food chain seems to be one of the most dangerous roads ${ }^{5}$. This transfer occurs through the plants and crops grown in contaminated soil. Therefore, cadmium is a danger to human health due to consumption of plants that can absorb it intensely and concentrate it in their tissues, especially plants that are known for their tolerance to cadmium. Food consumption is the main source for environmental contamination for the nonsmok-

Received: 13 May 2013, Accepted: 8 July 2013

*Corresponding author: S Haouem (e-mail: samirzeineb@yahoo.fr) (C)2013 The Japanese Society of Toxicologic Pathology

This is an open-access article distributed under the terms of the Creative Commons Attribution Non-Commercial No Derivatives (by-ncnd) License $<$ http://creativecommons.org/licenses/by-nc-nd/3.0/>. ing general population ${ }^{6}$

This pollutant has a wide spectrum of distribution. Indeed, it accumulates in various organs, the kidneys, liver, testes, pancreas, thyroid, salivary glands, bone and central nervous system. However, it is mainly concentrated in the liver and kidneys (between 50 and $75 \%$ of the total) 7 .

Previous studies have linked the toxic effects of this metal to oxidative stress, since it can alter the antioxidant defense system in several tissues in several animals, causing a decrease in glutathione levels and altered activity of antioxidant enzymes and a change in the structure of the cell membrane through a process of lipid peroxidation ${ }^{9,10}$. Most of this data were derived from experiments on animals treated with cadmium salts. However, to our knowledge, the studies of the effect of cadmium incorporated naturally in plants are very rare in the literature, while these works are more indispensable and more aware of the origin of human exposure, since vegetables are the main source of nonoccupational exposure of humans to heavy metal ${ }^{11}$.

So the purpose of this work was to study the accumulation of cadmium in the liver, kidneys and testes and its effect on lipid peroxidation and some antioxidant defense systems in male rats fed a diet containing cadmium incorporated into radish bulbs. 


\section{Materials and Methods}

\section{Diet preparation}

Two lots of radish bulbs were used to prepare diets for rats. One lot consisted of ordinary radishes: control radish bulbs. The second lot consisted of radishes contaminated with cadmium (via irrigation with water contaminated with $\mathrm{CdCl} 2$ ): contaminated radish bulbs. Before the two lots were incorporated into the diets, they were dried and ground into powders. Next, the control diet was prepared by mixing control radish bulb powder with granular flour at the rates of $5 \%$ and $95 \%$, respectively, while the contaminated diet was prepared by mixing contaminated radish bulb powder with granular flour at the same rates as the control diet. Chemical analysis showed that the control diet contained $0.01 \mathrm{mg}$ $\mathrm{Cd} / \mathrm{kg}$, while the contaminated diet contained $1.1 \pm 0.1 \mathrm{mg}$ $\mathrm{Cd} / \mathrm{kg}$.

\section{Animals and treatment}

Thirty-six male Wistar rats purchased from Siphat (Ben Arous, Tunisia) and weighing about $130 \mathrm{~g}$ were used in this study. Animals were housed individually in a room with the temperature $\left(22 \pm 2^{\circ} \mathrm{C}\right)$ and photoperiod (12-h light/dark cycle 07:00-19:00 h) controlled and allowed free access to the control diet. Five days later, the rats were separated into two groups: control and contaminated diet groups containing 18 rats each. Rats in the control group (control rats) continued to receive the control diet for a maximum period of 12 weeks, and rats in the contaminated group were given the contaminated diet for the same period as the control group. Diets and water were given ad libitum to rats. At the end of 4,8 and 12 weeks of treatment, six rats of each group were weighed and then euthanized by exsanguinations by severing the brachial artery under anaesthesia. The liver, kidneys and testes were removed quickly from animals, washed in ice-cold physiological saline, weighed and stored at $-80^{\circ} \mathrm{C}$. Animals were maintained during the experimental period in accordance with guidelines for animals care of the Faculté de Médecine de Monastir, Tunisia.

\section{Analytical procedure}

$\mathrm{Cd}$ determination: Cadmium concentrations in the liver, kidneys and testes were determined as described in our previous study ${ }^{12}$. Briefly, samples of the liver, kidneys and testes were dried to a constant weight. Then they were digested in concentric nitric acid. Once the digestion was complete, the samples were cooled at room temperature and brought to a constant volume $(5 \mathrm{ml})$ by adding deionized water. For cadmium determination, an atomic absorption spectrophotometer (Perkin-Elmer AAnalyst 100) was used.

Malondialdehyde (MDA) determination: The concentration of MDA in the $10 \%$ homogenates of the liver, kidneys and testes (prepared in phosphate buffer, $\mathrm{pH}=7.4$ ) was determined as thiobarbituric acid reactive substances (TBARS) according to Buege and Aust ${ }^{13}$.

Total glutathione (GSH) measurement: The concentration of GSH in the $10 \%$ homogenates of the liver, kidneys and testes (prepared in phosphate buffer $\mathrm{pH}=7.4$ ) was determined according to Beutler ${ }^{14}$.

Superoxide dismutase (SOD) activity: To determine the activity of SOD, the $10 \%$ homogenates of the liver, kidneys and testes (prepared in phosphate buffer, $\mathrm{pH}=7.4$ ) were centrifuged at $6500 \mathrm{rpm}$ at $4^{\circ} \mathrm{C}$ for $45 \mathrm{~min}$, and SOD activity was measured in the supernatant by the inhibition of nitroblue tetrazolium (NBT) reduction due to $\mathrm{O}_{2}$-generated by the xanthine/xanthine oxidase system ${ }^{15}$. One unit of SOD activity was defined as the amount of protein causing $50 \%$ inhibition of the NBT reduction rate.

\section{Statistics}

Data are expressed as means \pm SD. The values were analyzed by the nonparametric Mann-Whitney U test. Differences at $\mathrm{P} \leq 0.05$ were considered statistically significant.

\section{Results}

\section{Cadmium daily intake}

Based on the concentrations of cadmium in the control and contaminated diets and on the daily food consumption, which was approximately equal $120 \mathrm{~g} / \mathrm{kg} /$ day, the daily intakes of cadmium were $1.2 \mu \mathrm{g} / \mathrm{kg} /$ day and $132 \mu \mathrm{g} / \mathrm{kg} /$ day for the control and contaminated groups, respectively.

\section{Body weight gain}

The results presented in Table 1 indicate that the body weight gain of contaminated rats was similar to that of the control rats during the experimental period.

\section{Ratios of liver, kidney and testis weights to body weight}

The results presented in Table 1 indicate that the ratios of the liver, kidney and testis weights to body weight of contaminated rats were similar to those of the controls rats during the entire experimental period.

\section{Liver}

In the control rats, $\mathrm{Cd}$ was detected in the liver at very low levels (on an average of $0.03 \mathrm{mg} / \mathrm{g}$ dry weight), whereas in contaminated rats, the $\mathrm{Cd}$ concentration increased significantly $(\mathrm{P} \leq 0.01)$ and gradually from the 4 th $(0.74 \pm 0.18$ $\mathrm{mg} / \mathrm{g}$ dry weight) to the $12 \mathrm{th}(1.8 \pm 0.23 \mathrm{mg} / \mathrm{g}$ dry weight $)$ week of treatment (Table 2).

As shown in Table 2, the contents of MDA in the liver of rats of both groups were comparable after 4 and 8 weeks of treatment. By contrast, after 12 weeks of treatment, these contents were significantly lower $(\mathrm{P} \leq 0.05)$ in the treated rats compared with the corresponding controls.

The results in Table 2 indicate that the differences in the GSH concentrations in the liver between the contaminated rats and control rats after 4 and 8 weeks of treatment were not significant $(\mathrm{P} \geq 0.05)$. By contrast, after 12 weeks of treatment, these levels were significantly higher $(\mathrm{P} \leq 0.05)$ in contaminated rats compared with the orresponding controls.

Differences in SOD activity in the liver between the 
Table 1. Body Weight Gain and Ratios of Liver, Kidney and Testis Weights to Body Weight of Control and Contaminated Rats

\begin{tabular}{llccc}
\hline & \multirow{2}{*}{ Groups } & \multicolumn{3}{c}{ Period of treatment } \\
\cline { 3 - 5 } & & 4 weeks & 8 weeks & 12 weeks \\
\hline Body weight gain & Control & $46 \pm 10$ & $83 \pm 9$ & $107 \pm 22$ \\
(\%) & Contaminated & $41 \pm 11$ & $85 \pm 25$ & $108 \pm 22$ \\
Liver & Control & $4.06 \pm 0.55$ & $3.71 \pm 0.37$ & $3.28 \pm 0.25$ \\
$(\%)$ & Contaminated & $4.34 \pm 0.56$ & $3.87 \pm 0.14$ & $3.28 \pm 0.31$ \\
Kidney & Control & $0.85 \pm 0.07$ & $0.78 \pm 0.02$ & $0.71 \pm 0.04$ \\
$(\%)$ & Contaminated & $0.85 \pm 0.02$ & $0.78 \pm 0.05$ & $0.71 \pm 0.03$ \\
Testis & Control & $1.16 \pm 0.05$ & $0.94 \pm 0.08$ & $0.80 \pm 0.09$ \\
$(\%)$ & Contaminated & $1.19 \pm 0.05$ & $1.01 \pm 0.13$ & $0.81 \pm 0.04$ \\
\hline
\end{tabular}

Data are means $\pm \mathrm{SD}$.

Table 2. Cd Content and Changes in MDA and GSH Concentrations and SOD Activity in the Liver of Control and Contaminated Rats

\begin{tabular}{llccc}
\hline & Groups & \multicolumn{3}{c}{ Period of treatment } \\
\cline { 3 - 4 } & & 4 weeks & 8 weeks & 12 weeks \\
\hline \multirow{2}{*}{ Cd ( $\mu \mathrm{g} / \mathrm{g}$ dry weight) } & Control & $0.02 \pm 0.02$ & $0.03 \pm 0.02$ & $0.04 \pm 0.02$ \\
& Contaminated & $0.74 \pm 0.16^{* *}$ & $1.11 \pm 0.13^{* *}$ & $1.80 \pm 0.23^{* *}$ \\
MDA (nM/g fresh weight) & Control & $76.0 \pm 17.07$ & $83.1 \pm 18.9$ & $86.3 \pm 11.96$ \\
& Contaminated & $67.1 \pm 13.47$ & $81.42 \pm 16.68$ & $52.15 \pm 12.89^{*}$ \\
GSH (mg/g fresh weight) & Control & $1.38 \pm 0.36$ & $1.16 \pm 0.41$ & $\mathbf{0 . 8 1} \pm \mathbf{0 . 0 9}$ \\
& Contaminated & $1.24 \pm 0.47$ & $1.13 \pm 0.24$ & $1.29 \pm 0.26^{*}$ \\
SOD (U/g fresh weight) & Control & $1180 \pm 79.4$ & $1160 \pm 50.3$ & $1452 \pm 35.8$ \\
& Contaminated & $1148 \pm 179.3$ & $1020 \pm 129.1$ & $1480 \pm 61.1$ \\
\hline
\end{tabular}

Data are means $\pm \mathrm{SD} ;{ }^{*} \mathrm{P} \leq 0.05 ;{ }^{* *} \mathrm{P} \leq 0.01$.

Table 3. Cd Content and Changes in MDA and GSH Concentrations and SOD Activity in the Kidneys of Control and Contaminated Rats

\begin{tabular}{|c|c|c|c|c|}
\hline & \multirow{2}{*}{ Groups } & \multicolumn{3}{|c|}{ Period of treatment } \\
\hline & & 4 weeks & 8 weeks & 12 weeks \\
\hline \multirow{2}{*}{$\mathrm{Cd}(\mu \mathrm{g} / \mathrm{g}$ dry weight) } & Control & nd & nd & nd \\
\hline & Contaminated & $0.31 \pm 0.04^{* *}$ & $0.77 \pm 0.08^{* *}$ & $1.67 \pm 0.13^{* *}$ \\
\hline \multirow{2}{*}{ MDA (nM/g fresh weight) } & Control & $93.08 \pm 16.95$ & $87.22 \pm 11.05$ & $98.75 \pm 15.37$ \\
\hline & Contaminated & $106.58 \pm 7.99$ & $76.58 \pm 15.7$ & $135.17 \pm 27.16^{*}$ \\
\hline \multirow{2}{*}{ GSH (mg/g fresh weight) } & Control & $0.55 \pm 0.06$ & $0.60 \pm 0.04$ & $1.04 \pm 0.03$ \\
\hline & Contaminated & $0.58 \pm 0.15$ & $0.84 \pm 0.22$ & $0.77 \pm 0.06^{*}$ \\
\hline \multirow{2}{*}{ SOD (U/g fresh weight) } & Control & $1837 \pm 335.0$ & $1650 \pm 249.0$ & $1538 \pm 111.0$ \\
\hline & Contaminated & $1780 \pm 296$ & $1367 \pm 219$ & $2083 \pm 337.0^{*}$ \\
\hline
\end{tabular}

Data are means $\pm \mathrm{SD} ;{ }^{*} \mathrm{P} \leq 0.05 ;{ }^{* *} \mathrm{P} \leq 0.01$.

control rats and contaminated rats after 4, 8 and 12 weeks of treatment were not significant (Table 2).

\section{Kidneys}

In the control rats, $\mathrm{Cd}$ was not detected during the experimental period. In contrast, in the poisoned rats, the $\mathrm{Cd}$ concentration increased significantly $(\mathrm{P} \leq 0.01)$ and gradually from the 4th $(0.31 \pm 0.04 \mathrm{mg} / \mathrm{g}$ dry weight $)$ to the 12 th $(1.67 \pm 0.13 \mathrm{mg} / \mathrm{g}$ dry weight) week of treatment (Table 3$)$.

MDA levels in the kidneys of contaminated rats were comparable to those in the kidneys of the control rats after 4 and 8 weeks of treatment. However, after 12 weeks of treatment, a significant increase $(\mathrm{P} \leq 0.05)$ in these levels was ob- served in the kidneys of the treated rats compared with the control rats (Table 3 ).

As shown in Table 3, cadmium did not alter the concentrations of GSH in the kidneys of the treated rats compared with the control rats after 4 and 8 weeks of treatment. In contrast, after 12 weeks of treatment, we noted a significant decrease $(\mathrm{P} \leq 0.05)$ in GSH concentrations in the kidneys of contaminated rats compared with the corresponding controls.

As shown in Table 3, the SOD activity in the kidneys of rats of both groups was comparable after 4 and 8 weeks of treatment, whereas after 12 weeks of treatment, it showed a significant increase $(\mathrm{P} \leq 0.05)$ in contaminated rats compared 
Table 4. Cd Content and Changes in MDA and GSH Concentrations and SOD Activity in the Testes of Control and Contaminated Rats

\begin{tabular}{llccc}
\hline & Groups & \multicolumn{3}{c}{ Period of treatment } \\
\cline { 2 - 4 } & & 4 weeks & 8 weeks & 12 weeks \\
\hline \multirow{2}{*}{ Cd $(\mu \mathrm{g} / \mathrm{g}$ dry weight) } & Control & nd & nd & nd \\
& Contaminated & $0.18 \pm 0.03^{* *}$ & $0.37 \pm 0.04^{* *}$ & $0.64 \pm 0.05^{* *}$ \\
MDA (nM/g fresh weight) & Control & $81.11 \pm 11.65$ & $87.7 \pm 27.99$ & $72.8 \pm 7.47$ \\
& Contaminated & $79.13 \pm 13.5$ & $57.79 \pm 29.14$ & $98.04 \pm 11.33^{*}$ \\
GSH (mg/g fresh weight) & Control & $0.92 \pm 0.2$ & $0.94 \pm 0.11$ & $1.03 \pm 0.06$ \\
& Contaminated & $1.31 \pm 0.29$ & $1.19 \pm 0.2$ & $0.69 \pm 0.12^{*}$ \\
SOD (U/g fresh weight) & Control & $2369 \pm 489$ & $1872 \pm 433$ & $1915 \pm 350$ \\
& Contaminated & $2425 \pm 377$ & $2113 \pm 451$ & $2609 \pm 338^{*}$ \\
\hline
\end{tabular}

Data are means $\pm \mathrm{SD} ;{ }^{*} \mathrm{P} \leq 0.05 ;{ }^{* *} \mathrm{P} \leq 0.01$.

with the corresponding controls.

\section{Testes}

In the control rats, $\mathrm{Cd}$ was not detected during the experimental period. In contrast, in poisoned rats, the $\mathrm{Cd}$ concentration increased significantly $(\mathrm{p} \leq 0.01)$ and gradually from the 4 th $(0.18 \pm 0.03 \mathrm{mg} / \mathrm{g}$ dry weight $)$ to the 12 th $(0.64 \pm 0.05 \mathrm{mg} / \mathrm{g}$ dry weight) week of treatment (Table 4$)$.

The results in Table 4 show that the levels of MDA in the testes of contaminated rats were comparable to those in the testes of the control rats after 4 and 8 weeks of treatment. By contrast, after 12 weeks of treatment, these levels were significantly higher $(\mathrm{P} \leq 0.05)$ in the treated rats compared with the corresponding controls.

The results in Table 4 indicated that the GSH concentrations in the testes were comparable between the two groups of rats after 4 and 8 weeks of treatment. By contrast, after 12 weeks of treatment, these concentrations were significantly lower $(\mathrm{P} \leq 0.05)$ in the treated rats compared with the corresponding controls.

The differences in SOD activity in the testis between the control and contaminated rats after 4 and 8 weeks of treatment were not significant, while after 12 weeks of treatment, a significant increase was noted in contaminated rats compared with th corresponding controls (Table 4).

\section{Discussion}

Our results showed no difference in body weight gain between contaminated and control rats, which reflects that feeding rats with diet containing $\mathrm{Cd}$ incorporated in radish bulbs at the rate of approximately $1 \mathrm{mg} \mathrm{Cd} / \mathrm{g}$ dry weight of diet for up to 12 weeks (estimated achieved dosage: $132 \mu \mathrm{g} /$ $\mathrm{kg} /$ day) did not cause a retardation in the growth of rats. This may be explained by the low dose of $\mathrm{Cd}$ used, since the same result was obtained previously with a dose of $1 \mathrm{ppm}$ of cadmium chloride (approximately $1.6 \mathrm{ppm}$ of cadmium) added to drinking water and a period of up to 10 months ${ }^{16}$.

Many previous studies in several animal species showed that $\mathrm{Cd}$, after chronic exposure, is accumulated in liver, kidney and testis ${ }^{17,18}$. In agreement with these studies, our results showed that $\mathrm{Cd}$ was accumulated and detected in these three organs from the fourth week of treatment. It is well known that the organs of animals do not accumulate cadmium in the same way ${ }^{17}$. The results of the present study showed that throughout the experimental period, the highest concentrations of $\mathrm{Cd}$ were observed in the liver, followed by the kidney and the testis. This is in agreement with some previous studies that have reported that cadmium is concentrated mainly in the liver ${ }^{19,20}$. However it should be noted that the differences in the cadmium concentrations in the liver and kidney decrease as the duration of treatment increases. This can be explained by a gradual mobilization of cadmium from the liver to the kidney ${ }^{21}$.

The effect of $\mathrm{Cd}$ on the relative weights of the liver, kidneys and testes has been reported in several previous studies. Some studies have reported atrophy of the kidney, liver and testis ${ }^{4,22}$, while others have reported enlargement of these organs under the effect of cadmium ${ }^{20,23,24}$. The results presented in this study show that the $\mathrm{Cd}$ accumulated in these organs had no effect on the relative weights of the liver, kidneys and testes. This can be explained by the fact that the concentrations of $\mathrm{Cd}$ in theses organs are not enough to produce a change in the weights of the liver, kidneys and testes.

Several previous studies have linked cadmium to oxidative stress ${ }^{9,10}$. Therefore, the levels of MDA, an end product of lipid peroxidation, and some antioxidant defense systems were examined in the present study to find out whether cadmium incorporated into radish bulbs causes oxidative stress.

Our results showed a significant decrease in MDA levels in the liver of the contaminated rats compared with the control rats at the end of the study period. This excludes the possibility of an oxidative nature of this metal in the liver tissue. This confirms the work of Shibutani et al. ${ }^{25}$ and Kawagoe et al. ${ }^{19}$ carried out respectively in rats and mice, which showed that cadmium decreases lipid peroxidation in the liver of these animals. In contrast, other studies have reported an increase in lipid peroxidation in the liver under the influence of $\mathrm{Cd}^{25,26}$.

Along with the reduction of lipid peroxidation, we reported increased levels of GSH in this organ, while the activities of SOD were unchanged compared with the control 
rats. Kawagoe et al. ${ }^{19}$ also showed that cadmium increases hepatic GSH levels. The increase in GSH levels may be a result of high transcriptional regulation of $\gamma$-glutamylcysteine synthetase, the enzyme that is responsible for the synthesis of $\mathrm{GSH}^{27}$

The inversely proportional relationship between lipid peroxidation and GSH content in the liver will let us suggest that the decrease in lipid peroxidation observed in this work in the liver is due to increased synthesis of GSH due to cadmium. Indeed, GSH is part of a nonenzymatic defense system. It is a central protective antioxidant. GSH is considered the first line of defense against oxidative damage and free radical generation ${ }^{28}$. It can directly scavenge free radicals $^{29}$ or act as a substrate for glutathione peroxidase and glutathione S-transferase in the detoxification of hydrogen peroxide $^{30}$. The lack of effect of cadmium on the activity of SOD observed in our work can be explained by the short duration of the experiment or by low dose of cadmium used.

Unlike the liver, the kidneys and the testes of contaminated rats exhibited high levels of MDA compared with the control rats at the end of the experiment, which indicates an intensification of lipid peroxidation in these organs under the influence of $\mathrm{Cd}$. This is in agreement with several previous studies ${ }^{31-33}$. Parallel to this increase in MDA levels, we noted a decrease in GSH levels in the kidneys and testes of contaminated rats. This confirms the work of Koyutürk et $a l .{ }^{33}$ and El-Missiry and Shalaby ${ }^{34}$. On the other hand, we reported an increase in SOD activity in these organs at the end of the study period. These results contradict those of several previous studies ${ }^{35,36}$, which noted a decrease in the activity of this enzyme in the kidneys and testes of rats treated with $\mathrm{Cd}$. The increase in SOD activity may be interpreted as a protective response against cadmium toxicity In the kidneys and testes. Indeed, it has been shown that the activity of antioxidant enzymes behaves in two different ways during oxidative stress. At the beginning of stress, this activity increases, while in the long term, it is reduced due to the massive production of free radicals. This reduction is the result of damage to the molecular machinery that is required to induce these enzymes ${ }^{37,38}$.

The mechanism of induction of lipid peroxidation by cadmium is still poorly understood. As a transitional element, cadmium is unable to directly cause the formation of free radicals under physiological conditions ${ }^{39}$. So it probably acts through indirect mechanisms ${ }^{40}$. Based on the results of the present study, the increase in lipid peroxidation in the kidneys and testes might be attributable to the decrease in GSH levels.

In conclusion, the data of the present study suggest that cadmium incorporated in radish bulbs decreases hepatic lipid peroxidation but increases lipid peroxidation in the kidneys and testes of male rats.

Acknowledgments: This work was supported by research unit 04/UR/09-03 of the General Directorate Of Scientific and Technological Research of Tunisia.

\section{References}

1. Al-Alawi MM, and Mandiwana KL. The use of Aleppo pine needles as a bio-monitor of heavy metals in the atmosphere. J Hazard Mater. 148: 43-46. 2007. [Medline]

2. El-Sharaky AS, Newairy AA, Badreldeen MM, Eweda SM, and Sheweita SA. Protective role of selenium against renal toxicity induced by cadmium in rats. Toxicology. 235: 185-193. 2007. [Medline]

3. ATSDR Agency for Toxic Substances et Disease Registry: Public Health Statement for Cadmium. 1999. www.atsdr. cdc.gov/toxpro2/phs5.html.

4. Hwang DF, and Wang LC. Effect of taurine on toxicity of cadmium in rats. Toxicology. 167: 173-180. 2001. [Medline]

5. Eisler R. Cadmium. In: Handbook of Chemical Risk Assessment. Government, US (Ed). CRC Press, Florida. 1-43. 2000.

6. Goyer RA. Toxic effects of metals. In: Cassrett and Doull's Toxicology: The Basic Science of Poisons. J Doull, CD Klaassen, and MO Amdur (eds). Macmillian, New York. 582-635. 1986.

7. Friberg L, Nordberg GF, and Vouk VB. Handbook on the Toxicology of Metals, 2nd ed. Elsevier North Holland Biomedical Press, New York. 1986.

8. Reeves PG, and Rossow KL. Zinc and/or cadmium-induced intestinal metallothionein and copper metabolism in adult rats. Nutr Biochem. 7: 128-134. 1996.

9. Zikic RV, Stajn A, Saicic Z, Spasic M, Ziemnicki K, and Petrovic VM. The activities of superoxide dismutase, catalase and ascorbic acid content in the liver of goldfish (Carassius auratus gibelio bloch.) exposed to cadmium. Physiol Res. 45: 479-481. 1996. [Medline]

10. Bagchi D, Vuchetich PJ, Bagchi M, Hassoun EA, Tran MX, Trang L, and Stohs SJ. Induction of oxidative stress by chronic administration of sodium dichromate [chromium VI] and cadmium chloride [cadmium II] to rats. Free Radic Biol Med. 22: 471-478. 1997. [Medline]

11. Satarug S, Haswell-Elkins MR, and Moore MR. Safe levels of cadmium intake to prevent renal toxicity in human subjects. Br J Nutr. 84: 791-802. 2000. [Medline]

12. Haouem S, and Sakly R. Lactational transfer of cadmium from Meriones shawi shawi mothers to their pups and its effects on calcium homoeostasis and bone calcium in pups. Ann Nutr Metab. 49: 296-299. 2005. [Medline]

13. Buege JA, and Aust SD. Microsomal lipid peroxidation. Methods Enzymol. 52: 302-310. 1978. [Medline]

14. Beutler E. Glutathion in red blood cell metabolism. In: A Manual of Biochmemical Methods. 2nd ed. Grune and Stratton, New York. 112-114. 1975.

15. Sun Y, Oberley LW, and Li YA. Asimple method for clinical assay of superoxide dismutase. Clin Chem. 34: 497-500. 1988. [Medline]

16. Uriu K, Kaizu K, Qie YL, Ito A, Takagi I, Suzuka K, Inada Y, Hashimoto O, and Eto S. Long-term oral intake of lowdose cadmium exacerbates age-related impairment of renal functional reserve in rats. Toxicol Appl Pharmacol. 169: 151-158. 2000. [Medline]

17. Grosicki A. Influence of vitamin $\mathrm{C}$ on cadmium absorption and distribution in rats. J Trace Elem Med Biol. 18: 183-187. 2004. [Medline]

18. Damek-Poprawa M, and Sawika-Kapusta K. Damage to the liver, kidney, and testis with reference to burden of heavy 
metals in yallo-necked mice from areas aroud steel workers and zinc smelters in Poland. Toxicology. 186: 1-10. 2003. [Medline]

19. Kawagoe M, Hirasawa F, Wang SG, Liu Y, Ueno Y, and Sugiyama T. Orally administrated rare earth element cerium induces metallthionein synthesis and increases glutathione in the mouse liver. Life Sci. 77: 922-937. 2005. [Medline]

20. Pari L, and Murugavel P. Role of diallyl tetrasulfide in ameliorating the cadmium induced biochemical changes in rats. Environ Toxicol Pharmacol. 20: 493-500. 2005. [Medline]

21. Smith RM, Lech RM, Muller LD, Griel LC, and Baker DF. Effects of log-term dietary cadmium choride on tissue, milk and urine mineral concentrations of lactating dairy cows. $\mathrm{J}$ Anim Sci. 69: 4088-4096. 1991. [Medline]

22. Biswas NM, Gupta RS, Chattopadhyay A, Coudhury GR, and Sarcar M. Effect of atenolol on cadmium-induced testicular toxicity in male rats. Reprod Toxicol. 15: 699-704. 2001. [Medline]

23. Novelli EL, Vieira EP, Rodrigues NL, and Ribas BO. Risk assessment of cadmium toxicity on hepatic and renal tissues of rats. Environ Res. 79: 102-105. 1998. [Medline]

24. Zeng X, Jin T, Zhou Y, and Nordberg GF. Changes of serum sex hormone levels and MT mRNA expression in rats orally exposed to cadmium. Toxicology. 186: 109-118. 2003. [Medline]

25. Shibutani M, Mitsumori K, Satoh S, Hiratsuka H, Satoh M, Sumiyoshi M, Nichijima M, Katsuki Y, Suzuki J, Nakagawa J, Akagi T, Imazawa T, and Ando M. Relationship between toxicity and cadmium accumulation in rats given low amounts of cadmium chloride or cadmium- polluted rice for 22 months. J Toxicol Sci. 26: 337-358. 2001. [Medline]

26. Boujelben M, Gorbel F, Vincent C, Macni-Ayadi F, Guermazi F, Croute F, and El-Feki A. Lipid peroxidation and HSP72/73 expression in rat following cadmium chloride administration: Interactions of magnesium supplementation. Exp Toxicol Pathol. 57: 437-443. 2006. [Medline]

27. Eşrefoglu M, Gül M, Dogru MI, Dogru A, and Yürekli M. Adrenomedullin fails to reduce cadmium-induced oxidative damage in rat liver. Exp Toxicol Pathol. 58: 367-374. 2007. [Medline]

28. Mulcahy RT, and Gipp JJPL. Identification of a putative antioxidant response element in the 5-Flanking region on the human-glutamylcysteine synthetase heavy subunit gene. Biochem Biophys Res Commun. 209: 227-233. 1995. [Medline]

29. Bray TM, and Tayor CG. Tissue glutathione, nutrition and oxidative stress. Can J Physiol Pharmacol. 71: 746-751. 1993. [Medline]

30. Kalyanaraman B, Karoui H, Singh RJ, and Felix CC. Detec- tion of thiyl radical adducts formed during hydroxyl radical-and peroxynitrite-mediated oxidation of thiol --a high resolution ESR spin-trapping study at Q-band $(35 \mathrm{GHz})$. Anal Biochem. 241: 75-81. 1996. [Medline]

31. Ursini F, Maiorino M, Brigelius-Flohe R, Auman KD, Roveri A, Schomburg D, and Flohe L. Diversity of glutathione peroxidases. Methods Enzymol. 252: 38-53. 1995. [Medline]

32. Amara S, Abdelmalek H, Garrel C, Guiraud P, Douki T, Ravanat JL, Favier A, Sakly M, and Ben Rhouma K. Influence of static magnetic field on cadmium toxicity: Study of oxidative stress and DNA damage in rat tissues. J Trace Elem Med Biol. 20: 263-269. 2006. [Medline]

33. Santos FW, Oro T, Zeni G, Rocha JB, Do Nascimento PC, and Nogueira CW. Cadmium induced testicular damage and its response to administration of succimer and diphenyl diselenide in mice. Toxicol Lett. 152: 255-263. 2004. [Medline]

34. Koyuturk M, Yanardag R, Bolkent S, and Tunali S. Influence of combined antioxidants against cadmium induced testicular damage. Environ Toxicol Pharmacol. 21: 235240. 2006. [Medline]

35. El-Missiry MA, and Shalaby F. Role of $\beta$-carotene in ameliorating the cadmium-induced oxidative stress in rat brain and testis. J Biochem Mol Toxicol. 14: 238-243. 2000. [Medline]

36. Moralez AI, Vicente-Sanchez C, Sandoval JM, Egido J, Mayoral P, Arevalo MA, Fernandez-Tagarro M, LopezNovoa JM, and Perez-Barriocanal F. Protective effect of quercetin on experimental chronic cadmium nephrotoxicity in rats based on its antioxidant properties. Food Chem Toxicol. 44: 2092-2100. 2006. [Medline]

37. Casalino E, Calsaretti G, Sblano C, and Landriscina C. Molecular inhibitory mechanisms of antioxidant enzymes in rat liver and kidney by cadmium. Toxicology. 179: 37-50. 2002. [Medline]

38. Ikediobi CO, Badisa VL, Ayuk-Takem LT, Latinwo LM, and West J. Response of antioxidant enzymes and redox metabolites to cadmium-induced oxidative stress in CRL1439 normal bliver cells. Int J Mol Med. 14: 87-92. 2004. [Medline]

39. Eneman JD, Potis RJ, Osier M, Shukla GS, Lee CHB, and Chin JF. Suppressed oxidant-induced apoptosis in cadmium adopted alveolar epithelial cells and its potential involvement in cadmium carcinogenesis. Toxicology. 147: 215228. 2000. [Medline]

40. Casalino E, Sblano C, and Landriscina C. Enzyme activity alteration by cadmium administration to rats: the possibility of iron involvement in lipid peroxidation. Arch Biochem Biophys. 346: 171-179. 1997. [Medline] 